\title{
The mating systems of pinnipeds and marine iguanas: convergent evolution of polygyny
}

\author{
FRITZ AND KRISZTINA G. K. TRILLMICH \\ Max-Planck-Institut für Verhaltensphysiologie, Abt. Wickler, \\ D-8131 Seewiesen, W. Germany
}

\begin{abstract}
The convergent polygynous mating systems of marine iguanas and otariid pinnipeds depend on the existence of large female aggregations. These can build up where abundant marine food resources occur around oceanic islands which harbour fewer predators than continental areas. For marine iguanas distribution of food resources appears to determine the location of colonies, while for pinnipeds habitat choice is more decisive. In marine iguanas females benefit from gregariousness through reduced predation risk and social thermoregulation. In pinnipeds, sea lions may derive thermoregulatory benefits from gregariousness, while fur seals appear to be largely non-gregarious. In both groups males defend territories in areas of high female density. Large sexual size dimorphism presumably evolved in response to strong selection for high fighting potential of males. The capability to fast for prolonged periods of territory tenure is considered a secondary benefit of large male size, but not the driving force behind its evolution. We hypothesize that marginal males, through continuous sexual harassment of females that stay outside territories, have exerted pressure towards the evolution of female gregariousness.
\end{abstract}

KEY WORDS:-Sexual selection - evolution of polygyny - female gregariousness - Marine iguana - Pinnipeds.

\section{CONTENTS}

Introduction .

Factors responsible for female aggregation .

ponsible for female gregariousness .

Male competition and the evolution of sexual dimorphism . . . . . . . . 212

The genetical and ecological marginal male effects . . . . . . . . . . 215

Acknowledgements . . . . . . . . . . . . . . . . . . . . . .

References . . . . . . . . . . . . . . . . . . . . 216

\section{INTRODUCTION}

The main characteristics of the mating systems of marine iguanas and polygynous pinnipeds are surprisingly similar. In comparing these systems we place emphasis on comparison of marine iguanas with the two pinniped species found on Galapagos, the Galapagos fur seal (Arctocephalus galapagoensis) and the Galapagos sea lion (Zalophus californianus wollebaeki), although we are aware that these two are probably less polygynous and territorial than more 
temperate pinniped species. By studying similar social systems of widely different taxonomic groups, the selective forces shaping these systems often become more obvious and problem areas pinpointed (Wickler, 1973; Bradbury \& Vehrencamp, 1977). Furthermore, understanding important factors in one system may lead to the formulation of useful hypothesis for the other.

As female aggregation or gregariousness is basic to the evolution of polygyny in both groups (Bartholomew, 1970), factors moulding these traits will be considered first. In this article we distinguish between aggregation as a passive accumulation due to circumstances external to the animals, and gregariousness as an active tendency to search the proximity of others. While within aggregations the proximity of others need not be beneficial to the animals, any sufficient explanation of female gregariousness has to be based on the benefits females derive from actively approaching each other (Wittenberger, 1980).

\section{FACTORS RESPONSIBLE FOR FEMALE AGGREGATION}

Aggregations, if they are to be sustained over long periods of time, must have access to abundant food resources. Marine feeding provides pinnipeds, marine iguanas and seabirds alike with such a food resource which can be used by many animals.

Otariid pinnipeds (eared seals) with their extensive adaptations to an aquatic mode of life could spend most of their time in the water; however, they must come ashore for reproduction because the young are unable to survive in the water for some time after birth. For pinnipeds, reproduction is therefore one of the main reasons for coming ashore. This is clear for arctic and antarctic species, but is much less pronounced in the Galapagos species where even females without young haul out all year round in habitual colonies. In contrast to pinnipeds, marine iguanas are primarily terrestrial and colony sites, used by the animals throughout the year, are separated from egg-laying beaches where females aggregate only once a year. Thus, in marine iguanas reproduction cannot be the primary cause for the build-up of colonies ( $K$. Trillmich, 1983); rather colonies seem to build up close to rich foraging grounds in the intertidal zone.

Given the necessity to come or to stay ashore, aggregation in pinnipeds and marine iguanas is furthered by the limited mobility of the animals on land, making it costly to disperse inland where no great benefits can be obtained. Furthermore, tropical pinnipeds need to stay close to the water to be able to cool down during the heat of the day (White \& Odell, 1971; Gentry, 1973; F. Trillmich, in press). This leads to a linear spread of colonies along the coasts wherever suitable habitat is available.

As dense colonies of animals of limited mobility are likely to attract predators, only areas with low or no predation pressure can harbour female aggregations over extended periods. Such conditions are provided by oceanic islands devoid of mammalian predators. Due to their high mobility in water, pinnipeds can exploit a large area (which can support great numbers of animals) from one point on land; but the amount of coastline available on predation-free oceanic islands is small and this combination increases density on land.

These considerations make food and availability of suitable habitat the factors most likely to limit and therefore responsible for female aggregation. In marine 
iguanas, every colony has its own intertidal feeding area with very little or no overlap between colonies. Colonies on undisturbed islands are found almost everywhere where reefs and intertidal flats provide a rich feeding area. The distribution and abundance of food resources therefore seems to determine the location and size of marine iguana aggregations. Animals within an aggregation choose an area close to the foraging ground that meets their thermoregulatory requirements and this further increases density. There is no evidence that good foraging grounds would not be used because of lack of adequate land habitat nearby.

In pinnipeds feeding areas of adjacent colonies may largely overlap due to the high mobility of the animals in the water. Thus distribution of food resources is less likely to determine the location of female aggregations in pinnipeds. Feeding conditions may, however, determine the total number of animals that can successfully raise young by foraging in the vicinity of any one island. Pinnipeds show clear preference for the wind exposed side of oceanic islands and this factor alone already limits the area they can settle on land. In Galapagos, the sea lion and fur seal show very different habitat preferences. Sea lions prefer sandy beaches and appear to be using most of the ones suitably exposed to wind while fur seals need shade of caves or large boulders and are thus restricted to very rugged coasts. In the Galapagos fur seal female competition for preferred resting sites in the shade appears to limit population density on land ( $F$. Trillmich, in press).

This brief comparison shows that food resources and habitat choice are of differing importance in the determination of the size and distribution of aggregations of marine iguanas and pinnipeds.

\section{FACTORS RESPONSIBLE FOR FEMALE GREGARIOUSNESS}

Marine iguana and sea lion females are attracted to others of their species. When in a choice situation they prefer to approach other females rather than resting on an unoccupied, but apparently equally suitable site. While feeding conditions and habitat choice provide the necessary basis for build-up of female aggregations, these ecological factors do not explain why females are actually attracted to each other, i.e. are truly gregarious.

K. Trillmich (1983) suggested two reasons for true gregariousness in marine iguanas. (Firstly, marine iguana females reduce the risk of being preyed upon by hawks (Buteo galapagoensis) by living in large colonies. Such clumping together reduces the risk per individual of falling victim to a predator (Hamilton, 1971). Secondly, living in dense colonies helps marine iguanas thermoregulate. It has been shown that piling reduces overnight heat loss in marine iguanas (White, 1973; Boersma, 1982). Furthermore, during the night groups of females enter holes and cracks in the lava. In these poorly circulated micro-environments temperature and humidity may be increased, further minimizing the gradient for heat and water loss (White \& Lasiewski, 1971). The functional significance of keeping warm overnight presumably lies in more efficient food assimilation. These two advantages are true benefits available to marine iguanas only through gregariousness. As they also apply to marine iguana males it is not surprising to observe that males, outside the breeding season, are just as gregarious as females. We believe that these benefits were not 
the primary causes for build-up of colonies in marine iguanas, but led to the evolution of gregariousness only once aggregations were established for the reason discussed above.

In contrast to marine iguanas, no adequate explanation for gregariousness in pinnipeds has been suggested. Bartholomew (1970) only refers to an "inherent tendency to aggregate" in pinnipeds but offers no explanation for the phenomenon. Gentry (1975) has pointed out that sea lions and fur seals show very different patterns of gregariousness. Galapagos sea lion females returning from foraging trips push into the middle of clumps of resting sea lions. This behaviour contrasts sharply with that of fur seal females which aggressively space out as much as possible (Mattlin, 1978; Francis \& Gentry, 1981; F. Trillmich, in press).

One explanation for this difference between sea lions and fur seals may lie in different thermoregulatory requirements. While at sea, constriction of peripheral blood vessels allows the blubber layer to act as a strong heat retaining insulator. On land full circulation of blood to the skin is restored. This is necessary for epidermal cell production since these cells undergo mitosis only in warm skin (Feltz \& Fay, 1966). Because of their sparse fur, sea lions can dissipate large amounts of heat to cooler surroundings while resting on land. Heat loss is reduced by resting in contact with other sea lions. Since these animals spread out and lie singly when air temperatures or solar radiation increase (Gentry, 1973; own obs.) the primary function of huddling appears to be reduction of heat loss. In fur seals, however, the skin is always kept warm by the insulation provided by air trapped in the dense underfur. This makes huddling unnecessary and may even make it dangerous by preventing fur seals from unloading metabolic heat via their (exposed) flippers; this might explain their avoidance of body contact. Thus, as with marine iguanas, gregariousness in sea lions may have a thermoregulatory basis. This hypothesis cannot explain why the South African fur seal (Arctocephalus pusillus), which in many ways resembles sea lions, huddles although it has underfur.

Sea lion females with young pups, which are susceptible to attacks by other animals, become less gregarious and exhibit territoriality until the pups are strong enough to join the crowd (Peterson \& Bartholomew, 1967). Fur seal females are also most aggressive shortly after birth of pups (Francis \& Gentry, 1981) and the same has been observed for elephant seal females (Bartholomew, 1952). Thus reproduction brings pinnipeds on land, but inhibits gregarious behaviour.

Another benefit of gregariousness for sea lion, fur seal and perhaps marine iguana females alike has presumably developed as the polygynous system evolved and is referred to as the 'ecological marginal male effect'. This is discussed below.

\section{MALE COMPETITION FOR ACCESS TO FEMALES AND THE EVOLUTION OF SEXUAL DIMOR PHISM}

In pinnipeds males cannot monopolize access to females in an economical manner by defending feeding territories, since females forage singly and their high mobility in the water allows them to forage over a wide area, making the density of foraging females extremely low. In marine iguanas, ectothermy 
prevents males from monopolizing females by means of feeding territoriality in the intertidal or in shallow water close to the coast since they cool down rapidly when in the water (Bartholomew, 1966) and a cold marine iguana is too sluggish to fight and perhaps even to copulate.

In pinnipeds and marine iguanas the dense aggregations of more or less gregarious females therefore form the basis for male-male competition for access to females. Another necessary precondition for the evolution of a high degree of male polygyny is the complete absence of male parental care (Trivers, 1972; Emlen \& Oring, 1977). The example of sea birds, which also live in densely aggregated colonies, shows that freedom from paternal care really is a necessary condition. No polygyny has evolved in seabirds which cannot raise young successfully without substantial brood care by the male. Bartholomew (1970) mentioned the absence of paternal behaviour in pinnipeds, but unfortunately did not include it in the explicit formulation of his model. The absence of paternal care has been questioned by Barlow $(1972,1974)$ for the Galapagos sea lion. Eibl-Eibesfeldt (1955) and Barlow (1972) each observed one instance where territorial bulls appeared to be herding pups ashore and attacked a shark. During more than seven months of observations in sea lion colonies we did not observe a single instance of this behaviour, suggesting that it is very rare. During this time, however, resting and feeding non-territorial sea lions and fur seals, some of them immatures, were observed to mob sharks. As even adult sea lions are often seen with shark-bite injuries, sharks can apparently be very dangerous even to adult animals. But a detected shark can be attacked and chased away without great risk, due to the superior manoeuvering powers of seals. We therefore prefer to interpret the observations by Barlow and Eibl-Eibesfeldt as self-protective mobbing behaviour. Consequently we accept the absence of paternal care as a general and important pre-adaptation for the evolution of polygyny in pinnipeds, just as in marine iguanas where males do not even come close to egg-laying sites and have little or no contact with hatchlings.

Given that female aggregations exist and males have no responsibilities for their offspring, selection will favour males which gain access to and copulate with the largest number of females in the aggregation. In response to this selective pressure marine iguanas and pinnipeds have evolved strikingly similar patterns of male territoriality. During the mating season males, through often violent fights, establish territories in areas of high female density excluding a large section of the male population from access to sexually receptive females. This leads to very skewed sex ratios in the breeding colonies and potentially high copulatory success of territorial males. Females are essentially free to move between territories and do so quite frequently. Therefore the term 'harem' often applied to the females found on a male's territory is inappropriate (Peterson, 1968). Rather, males defend suitable habitat which is a valuable resource for females (K. Trillmich, 1983; F. Trillmich, in press). Only the best fighting males succeed in the competition for access to females. Non-territorial males may occasionally intercept a receptive female, but their probability of copulation is extremely low in comparison to that of territorial males. Reproductive success of a male thus becomes dependent on his territorial success.

One of the most important factors promoting male territorial success is fighting potential, which largely depends upon size. As a consequence only the largest 
and most successful fighting males sire offspring. This situation creates a positive feedback of selection for ever larger size of males (Bartholomew, 1970). In marine iguanas territorial males are on average about 2.5 times as heavy as females (K. Trillmich, 1983) and the same may be true for Galapagos sea lions, although measurements of male weights do not exist. In the Galapagos fur seal, size dimorphism is least pronounced, with territorial males averaging about twice as heavy as females. This size dimorphism is small in comparison to the northern fur seal (Callorhinus ursinus) where males are about six times as heavy as females.

As size dimorphism in pinnipeds has remained relatively constant since the Miocene (Bartholomew, 1970) the loop of positive feedback of selection for increased male size must have been opened. The same probably applies to marine iguanas. The maximal size which a male marine iguana can reach may be constrained by competition for limiting food resources during the less productive warm season (K. Trillmich, 1983). In Galapagos fur seals, large territory size and the accompanying high cost of locomotion, as well as thermoregulatory constraints on highly active bulls are assumed to have decreased the sexual size dimorphism to less than that observed in the South American fur seal (Arctocephalus australis), from which the Galapagos species evolved (F. Trillmich, in press). The factors which have opened the positive feedback loop in Galapagos sea lions are unknown. Galapagos sea lions largely circumvented the problems of thermal stress and high locomotion cost by establishing partly aquatic territories which are patrolled by swimming back and forth in front of the beach.

Large size, with its accompanying lower weight-relative metabolism, leads to an increased capacity for prolonged fasting. By defending their territories for prolonged periods territorial males exclude even more males from the females. In fasting pinnipeds an enormous blubber layer provides a large store of energy. Marine iguanas have much smaller fat stores, but their lower metabolic rate (compared to mammals) also allows them to fast for long periods. One exceptional territorial marine iguana was observed to fast for at least 49 days. Their physiology thus provides marine iguanas with a different solution to the same problem which territorial pinnipeds face. In Bartholomew's model, fasting capability and fighting potential of males are of about equal importance in the evolution of size dimorphism and polygyny. In the light of observations on marine iguanas and Galapagos pinnipeds, this seems questionable. Most successfully copulating territorial marine iguana males fasted for only relatively short bouts and left their territories several times during the mating season to forage. The same was observed in Galapagos sea lions in low density colonies. As the breeding season of this species lasts for about 6-10 months in any given colony no male can possibly fast for such a long period. Nevertheless, the polygynous breeding system and male territoriality have not disintegrated. Rather, in low-density colonies, males leave their territories during the day, when most females are away from the rookery foraging, and return in the late afternoon shortly before the main arrival of females. In this way they manage to hold territories for up to three months. In high-density colonies territorial male Galapagos sea lions conform more to the usual pattern by staying for a shorter, continuous period. They may, however, return several times during a season to claim the same territory. Although Galapagos fur seals have a shorter breeding 
season, of about three months, males holding territories early in the season may come back to reclaim their territories after having fattened up at sea for 4-6 weeks.

These observations show that in marine iguanas and Galapagos sea lions continuous attendance on territory is not as important for male reproductive success as fighting potential. As K. Trillmich (1983) postulated for marine iguanas, increased fasting ability does not appear to be the driving force behind the selection for large size in males, but rather a consequence of the selection for high fighting potential.

\section{THE GENETICAL AND ECOLOGICAL MARGINAL MALE EFFECT}

Bartholomew (1970) suggested that females will choose territorial males and avoid copulation with excluded (marginal) males. In so doing they presumably increase the probability of bearing young with 'good genes' as territorial bulls are of proven (phenotypical) quality. This factor, called the (genetical) marginal male effect, should increase female gregariousness as females would benefit from gathering around territorial males. There are some theoretical problems with this idea (Williams, 1966; Maynard-Smith, 1978), but Cox \& LeBoeuf (1977) have described a mechanism of female choice in northern elephant seals (Mirounga angustirostris) and females of marine iguanas and Galapagos fur seals were observed to try to avoid copulations with marginal males. There is, however, no indication of female choice between territorial males in marine iguanas ( $\mathbf{K}$. Trillmich, 1983) or Galapagos fur seals (pers. obs.).

Another marginal male effect was observed in Galapagos sea lions and fur seals which selects for increased female gregariousness via ecological effects. We therefore call it the ecological marginal male effect. In most polygynous pinniped species for which data exist, females away from territories, whether in oestrus or not, are constantly harassed by marginal males. This sexual harassement can lead to the death of a female, but even under usual circumstances frequent disturbances by marginal males create high costs for females. These costs consist of expenditure of time and energy in fending off these over-zealous males, and risk of injury and separation from pups. This contrasts with the small benefit females may derive from decreased competition with other females. Choosing an area defended by a strong territorial male protects pinniped females from copulation attempts by marginal males. This benefit will act to concentrate females into the areas claimed by territorial males. It results in selection for gregariousness in species where females otherwise do not derive direct benefits from association with each other, as suggested above for fur seals. This effect could also explain why, of two apparently equally suitable beaches, only the beach occupied by territorial males is used by females. A similar effect may be operative in marine iguanas but has not been very clearly observed.

\section{ACKNOWLEDGEMENTS}

The work on which this paper is based was done in Galapagos between 1976 and 1981 with the permission of the Galapagos National Park and the support 
of the Charles Darwin Research Station. We would like to thank the Park Intendentes Miguel Cifuentes and Fausto Cepeda and the directors of the Charles Darwin Station Drs. Craig MacFarland, Hendrik N. Hoeck and Friedemann Koester for their continuous friendship and help. We greatly appreciate the critique and suggestions that George A. Bartholomew, Jack Bradbury, Fred N. White and Terry Williams made to various versions of this manuscript. This study was supported by the Max-Planck Gesellschaft and is contribution no. 363 of the Charles Darwin Foundation for the Galapagos.

\section{REFERENCES}

BARLOW, G. W., 1972. A paternal role for bulls of the Galapagos islands sea lion. Evolution, 26: 307-308.

BARLOW, G. W., 1974. Galapagos sea lions are paternal. Evolution, 28: 476-478.

BARTHOLOMEW, G. A., 1952. Reproductive and social behaviour of the northern elephant seal. University of California Publications in Zoology, 47: 369-472.

BARTHOLOMEW, G. A., 1966. A field study of temperature relations in the Galapagos marine iguana. Copeia, 2: 241-250.

BARTHOLOMEW, G. A., 1970. A model for the evolution of pinniped polygyny. Evolution, 24: 546-559.

BOERSMA, P. D., 1982. The benefits of sleeping aggregation in marine iguanas. Amblyrhynchus cristatus. In G. M. Burghardt \& A. S. Rand, (Eds), Iguanas of the World: 292-299. Park Ridge, New Jersey, U.S.A.: Noyes Publications.

BRADBURY, J. W. \& VEHRENCAMP, S. L., 1977. Social organization and foraging in Emballuronid bats. III. Mating systems. Behavioral Ecology and Sociobiology, 2: 1-17.

COX, C. R. \& LEBOEUF, B. J., 1977. Female incitation of male competition: a mechanism of mate selection. American Naturalist 111: 317-335.

EIBL-EIBESFELDT, I., 1955. Ethologische Studien am Galapagos-Seelowen, Zalophus wollebaecki Sivertsen. Zeitschrift für Tierpsychologie, 12: 286-303.

EMLEN, S. T. \& ORING, L. W., 1977. Ecology, sexual selection, and the evolution of mating systems. Science, 197: 215-223.

FELTZ, E. T. \& FAY, F. H., 1966. Thermal requirements in vitro of epidermal cells from seals. Cryobiology, 3: $261-264$

FRANCIS, J. M. \& GENTRY, R. L., 1981. Interfemale aggression in the northern fur seal, Callorhinus ursinus. Abstract, Fourth Biennial Conference Biology of Marine Mammals, San Francisco, 1981.

GENTRY, R. L., 1973. Thermoregulatory behaviour of eared seals. Behaviour, 46: 73-93.

GENTRY, R. L., 1975. Comparative social behaviour of eared seals. Rapports et Procès-Verbaux des Réunions. (Conseil permanent International pour l'Exploration de la Mer.), 169: 188-194.

HAMILTON, W. D., 1971. Geometry for the selfish herd. Journal of Theoretical Biology, 31: 295-311.

MATtLin, R. H., 1978. Population biology, thermoregulation and site preference of the New Zealand fur seal, Arctocephalus forsteri (Lesson, 1828) on the Open Bay Islands, New Zealand. Ph.D.Thesis, University of Canterbury, U.K.

MAYNARD-SMITH, J., 1978. The Evolution of Sex. Cambridge: Cambridge University Press.

PETERSON, R. S., 1968. Social behaviour in pinnipeds with particular reference to the northern fur seal. In R. J. Harrison, R. C. Hubbard, R. S. Peterson, C. E. Rice \& R. J. Schusterman (Eds), The Behaviour and Physiology of Pinnipeds: 3-53. New York: Appleton-Century-Crofts.

PETERSON, R. S. \& BARTHOLOMEW, G. A., 1967. The natural history and behaviour of the California sea lion. American Society of Mammalogist, Spec. Publ. No. 1.

TRILLMICH, F., in press. The natural history of the Galapagos fur seal (Arctocephalus galapagoensis, Heller 1904). In R. Perry (Ed.), Key Environment Series: Galapagos. Oxford: Pergamon Press.

TRILLMICH, K. G. K., 1983. The mating system of the marine iguana (Amblyrhynchus cristatus). Zeitschrift für Tierpsychologie, 63: 141-172.

TRIVERS, R. L., 1972. Parental investment and sexual selection. In B. Campbell (Ed.), Sexual Selection and the Descent of Man: 139-179. Chicago: Aldine.

WHITE, F. N., 1973. Temperature and the Galapagos marine iguana. Insights into reptilian thermoregulation. Comparative Biochemistry and Physiology, 45: 503-513.

WHITE, F. N. \& LASIEWSKI, R. C., 1971. Rattlesnake denning: theoretical considerations in winter temperatures. Fournal of Theoretical Biology, 30: 553-557.

WHITE, F. N. \& ODELL, D. K., 1971. Thermoregulatory behaviour of the northern elephant seal, Mirounga angustirostris. Journal of Mammalogy, 52: 758-774.

WICKLER, W., 1973. Ethological analysis of convergent adaptation. Annales of the New York Academy of Sciences, 223: 65-69.

WILLIAMS, G. C., 1966. Adaptation and Natural Selection. Princeton, N. J.: Princeton University Press.

WITTENBERGER, J. F., 1980. Group size and polygamy in social mammals. American Naturalist, 115: 192-222. 